\title{
Global collaboration between Tanzania and Japan to advance midwifery profession: A case report of a partnership model
}

\author{
Yoko Shimpuku ${ }^{* 1}$, Shigeko Horiuchi ${ }^{1}$, Sebalda C. Leshabari ${ }^{2}$, Dickson Mkoka ${ }^{2}$, Yasuko Nagamatsu ${ }^{1}$, Miwako \\ Matsutani ${ }^{1}$, Hiromi Eto ${ }^{3}$, Michiko Oguro ${ }^{1}$, Yukari Yaju ${ }^{1}$, Mariko lida ${ }^{1}$, Columba Mbekenga ${ }^{1}$, Lilian Mselle ${ }^{2}$, Agnes \\ Mtawa $^{4}$ \\ ${ }^{1}$ College of Nursing, St. Luke's International University, Tokyo, Japan \\ ${ }^{2}$ School of Nursing, Muhimbili University of Health and Allied Sciences, Dar es Salaam, Tanzania \\ ${ }^{3}$ Graduate School of Biomedical Sciences, Nagasaki University, Nagasaki, Japan \\ ${ }^{4}$ Muhimbili National Hospital, Dar es Salaam, Tanzania
}

Received: May 16, 2015

DOI: $10.5430 /$ jnep.v5n11p1

\begin{abstract}
Accepted: July 12, 2015
Online Published: August 6, 2015
\end{abstract}

URL: http://dx.doi.org/10.5430/jnep.v5n11p1

\begin{abstract}
The global health agenda to reduce maternal mortality is delayed in Sub-Saharan Africa. The shortage of skilled birth attendants in Tanzania hinders the improvement of midwifery care to prevent maternal mortality and morbidity. It is urgently neccesary to develop midwifery leaders capable of working as educators, researchers, administrators, and advanced practitioners, contributing to the improvement of midwifery care and maternal child health in their own country. This report describes the process of establishing the first midwifery master's program in Tanzania through the efforts of two academic institutions, one in Tanzania and one in Japan. The collaboration developed a sustainable partnership model for the advancement of midwifery education. This partnership model was based upon the professional relationships corresponding with our values of humanized childbirth and people-centered care. The key elements for the project success included: (1) spending adequate time for in-person communication with the collaborative partner; (2) sharing the same goals and concepts; (3) understanding different values and norms for working and living; (4) learning ways of communication and project implementation in the partner's culture and (5) confirming the feasibility, which could increase team members' motivation and commitment. Midwives from the two institutions both gained knowledge and research outcomes as well as the satisfaction of establishing the midwifery master's program. To improve the remaining global maternal health issues, this win-win collaboration should be considered as the 21 st century's partnership model for the global health community.
\end{abstract}

Key Words: Midwifery education, Maternal mortality, Collaboration, Partnership, Tanzania, Africa

\section{INTRODUCTION}

It has been 30 years since the 1985 publication of "Where is the $\mathrm{M}$ in $\mathrm{MCH}$ ?" which pointed out the striking delay in improvement of maternal mortality in developing countries. ${ }^{[1]}$ The Millennium Development Goals (MDGs) were set in 2000, and the MDGs evaluation began in 2015 to set a new goal for 2030. The $2014 \mathrm{MDGs}$ report ${ }^{[2]}$ showed that almost 300,000 women still died in 2013 due to pregnancy and childbirth. There has been a $45 \%$ reduction of maternal mortality in developing countries, but as the 5th MDG was

*Correspondence: Yoko Shimpuku; Email: yoko-shimpuku@slcn.ac.jp; Address: College of Nursing, St. Luke’s International University, 10-1 Akashi cho, Chuo ku Tokyo, 104-0044, Japan. 
defined as a 75\% reduction in maternal mortality from 1990 to 2015 , much more effort is needed to boost improvement.

In Tanzania, a recent report estimated the maternal mortality ratio was 454/100,000 live births, noting it was only a slight five-year decline. ${ }^{[3]}$ Currently the key strategy to reduce maternal mortality is to increase the number of births with skilled birth attendants (SBAs), who are accredited health professionals mainly midwives, doctors, or nurses. ${ }^{[4]}$ The recent data, however, suggests that only $50.6 \%$ of all women were assisted by SBAs. Although $79.6 \%$ of births were conducted in rural areas of Tanzania, only $42.3 \%$ of all deliveries were conducted by SBAs. ${ }^{[3]}$ In other words, more than half of rural women have no access to SBAs while giving birth.

The shortage of SBAs with the increasing number of pregnant or birthing women coming to the Tanzanian hospitals challenges hospitals' resources. It was reported that Tanzanian nurses provide inadequate care for patients because of a heavy workload. ${ }^{[5]}$ Even in the largest city, where health care providers are likely to have the highest patient to nurse ratio, it was found that one nurse carries the equivalent responsibilities of five nurses. ${ }^{[6]}$ Since many SBA's are attracted and recruited to urban areas and other countries, ratios are even higher in rural areas of Tanzania. ${ }^{[7]}$

The health sectors in Tanzania recognized the severe shortage of midwives and have given priority to increasing the number of midwives with life-saving skills and other competencies. To achieve universal access to sexual, reproductive, maternal, and newborn care, midwives must respond to 3.6 million pregnancies per year by 2030, representing a 39\% increase from 2012. ${ }^{[8]}$ Currently, there are great needs in improving the quality of midwifery education; however a lack of skilled faculty constrains the implementation.

With inadequate resources and understaffing, the quality of childbirth care also faces challenges ${ }^{[9-11]}$ Tanzanian nurses stated that adequate education and supervision for new nurses as well as continuing education were not available to them, which caused feelings of discomfort and disinclination because they could not keep up with medical developments and use new scientific knowledge and proven methods to care for their patients. ${ }^{[5]}$ For example, it was reported that women were less mobile during childbirth in hospitals compared to those at home, and that the supine position was routinely used for deliveries in hospitals. ${ }^{[12]}$ This practice is incongruent with the World Health Organization practical childbirth guide. ${ }^{[13]}$ The guideline endorses providing an environment that ensures the rights and choices of birthing women. Unfortunately, in reality there are still gaps in meeting women' needs; for example, neglect and abusive language or be- haviors were observed in clinical settings. ${ }^{[14,15]}$ This issue of quality of care is common across developing countries, which led to the WHO's recent statement of Prevention and elimination of disrespect and abuse during childbirth. ${ }^{[11]}$ Providing adequate education and supportive work environments to maximize safe midwifery care can begin to be addressed through collaboration with a developed country. ${ }^{[16]}$ At the 2010 63rd World Health Assembly (WHA63.16), the WHO Global Code of Practice on the International Recruitment of Health Personnel promulgated in the Guiding Principles that, "Developed countries should, to the extent possible, provide technical and financial assistance to developing countries and countries with economies in transition aimed at strengthening health systems, including health personnel development. ${ }^{[17]}$ ",

\section{Global collaboration}

To develop the relationship between a donor country and a host country, De Santis ${ }^{[18]}$ presented the concept of "counterpart" to provide the framework for development of international nursing programs. The key components of the concept include the following: (1) negate the need for the donor group in the host country; (2) address the needs, available resources and developing potential of the host country community or group; (3) address sociocultural, political and economic factors in the partnership planning process; and (4) develop nurses from both the donor group and the host country involved in the partnership to their fullest potential. Based on De Santis' concept, a study reviewed nine nursing partnership projects and found that all of them included the components above. However, equality between the host country and the donor country was controversial in several studies in terms of the unequal decision-making process. ${ }^{[19]}$ Another review found more issues, such as distance, communication, cultural differences, and historical context that emerged and created challenges to their success. ${ }^{[20]}$

For successful collaborations, researchers have identified that all stakeholders needed to build trust among partners and to establish local capacity to ensure lasting and sustainable outcomes once the initial period of engagement has ended. ${ }^{[20]}$ Other researchers emphasized leadership as the key to initiating and sustaining social change and that teamwork including shared responsibility, mutual respect, open communication, compromise and capitalizing on partner strengths must go hand-in-hand with leadership. ${ }^{[21]}$ These elements form a framework for this case study where two institutions, one in Tanzania and one in Japan formed a collaborative relationship from 2011 to 2015 using a partnership model to advance midwifery education in Tanzania. We identify successful factors for international collaboration and partnership drawn from reflections on our experiences. 


\section{Method}

\subsection{Case description}

United Nations Population Fund stated that lack of professional development hinders the attractiveness of the midwifery profession. ${ }^{[8]}$ In a similar vein the International Council for Nurses also identified that the opportunity of professional development is one of the factors that attract women to recruit and retain a nurses. ${ }^{[22]} \mathrm{A}$ case in point was that in Tanzania, graduate programs in the midwifery specialty were not available, and therefore the opportunity of professional development for midwives was limited. To increase the number of faculty and to provide professional development for midwives, Muhimbili University of Health and Allied Sciences urgently needed to develop a master's program in midwifery.

This project aimed to develop the midwifery master's program in Muhimbili University of Health and Allied Sciences (MUHAS). MUHAS is the national medical university established in 1991, formerly called Muhimbili University College of Health Sciences (MUCHS). The School of Nursing offered three bachelor's degree programs and two master's degree programs at the start of the project in 2011. The counterpart of this project, Dr. Author has been committed to enhancing midwifery education. Although there were several midwifery faculty including Dr. Author who had graduate education outside the country, it was a rare opportunity to study abroad to obtain a higher degree due to the financial constraints.

\subsection{Asia Africa midwifery research center}

St. Luke's developed its master's program in midwifery in 1983 and henceforth developed numerous midwifery researchers. In 1990 St. Luke's College of Nursing was appointed as the WHO Collaborating Center for Nursing Development in Primary Health Care and began accepting researchers and students from developing countries. In 2009 a Tanzanian midwife entered the master's program in women's health and midwifery in St. Luke's. Her research project was a reproductive health education program for adolescent boys and girls in urban areas of Tanzania. ${ }^{[23]}$ Her presence helped instigate the institutional relationship. In December 2009, MUHAS and St. Luke's signed the Memorandum of Understanding to establish cooperative relations between the two institutions. This led to MUHAS faculty providing supervision for several graduate students from St. Luke's conducting similar research in Tanzania. Following several years of successful contact, MUHAS and St. Luke's decided to develop the master's program in midwifery at MUHAS for their first collaborative project. To support the project St. Luke's wrote a grant for funding.
The grant from the Japan Society for the Promotion of Science, Asia Africa Science Platform Program was for the period of 2011-2013. Its goal was the sustainable development of novice researchers who would contribute to evidencebased midwifery for the promotion of maternal child health in Tanzania (principle investigator: Author). We established the Asia Africa Midwifery Research Center to house the grant. Our mission included the following: 1) conducting research about midwifery and women's health to improve reproductive health of women in Asia and Africa, 2) promoting collaboration of reproductive health researchers in Asia and Africa, and 3) development of novice researchers for the future of reproductive health research.

\subsection{Outline of the project}

In the beginning, the input-output model among students, educators, and environment was depicted to achieve the transformation in midwifery education in Tanzania (see Table 1) and was presented at a conference. ${ }^{[24]}$ According to the grant, the center was assigned to conduct exchanges, seminars, and research collaboration. Figure 1 shows the outline of the project between 2011-2015.

\section{RESUltS}

\subsection{Exchange program in Japan}

When MUHAS faculty visited St. Luke's in 2011, Japanese faculty and students aimed to share about midwifery education and practices in Japan. The midwifery faculty guests from Tanzania were invited to attend classes in midwifery and the master's level global health nursing classes. In addition, St. Luke's faculty provided individual special classes in nursing education, midwifery education, and evidence-based practice. A guest lecturer, Ms. Taeko Mohri, provided the lecture on humanized childbirth through her experience with the successful Projet Luz (project light) in Brazil. ${ }^{[25]}$ As she described the improvements humanized childbirth made for midwifery in Brazil, which was once the poorer country, all of the Tanzanian faculty were motivated to change their own country and requested that their Japanese counter-parts present the topic in Tanzania. After the lecture, they had opportunities to observe a midwifery-led birth clinic and a community birth center, in which the guests learned how Japanese midwives implemented humanized childbirth care in everyday practice. They also visited the Japan International Cooperation Agency (JICA) Headquarters to learn about Japanese Official Development Assistance projects in Tanzania. 
Table 1. Input-output model to achieve transformation in midwifery education in Tanzania

\begin{tabular}{|c|c|c|c|}
\hline & Inputs & Process & Outputs \\
\hline Students & $\begin{array}{ll}\text { Entry requirement } \\
\text { - } & \text { Students with bachelor degree } \\
\text { - } & \text { Minimum GPA } 2.7 \\
\text { - } & \text { A graduate of a recognized university }\end{array}$ & $\begin{array}{l}\text { Learn followings: } \\
\text { Advanced midwifery } \\
\text { (concept, theory, and practice) } \\
\text { - } \quad \text { EBP-5 steps } \\
\text { - } \quad \text { Research methods } \\
\text { - } \quad \text { Biostatistics \& Bioethics } \\
\text { - } \quad \text { Nursing education } \\
\text { - } \quad \text { Leadership \& management }\end{array}$ & $\begin{array}{l}\text { Midwives with Master's degree } \\
\text { - } \quad \text { Educator } \\
\text { - } \quad \text { Clinical practitioner } \\
\text { - } \quad \text { Translational Researcher } \\
\text { Administrator }\end{array}$ \\
\hline Educators & $\begin{array}{l}\text { All educators are Masters or PhD qualified } \\
\text { Competent to teach and supervise students }\end{array}$ & $\begin{array}{l}\text { Teach Master-level midwives using } \\
\text { adult learning methods } \\
\text { Develop and use new teaching } \\
\text { methods }\end{array}$ & $\begin{array}{l}\text { Increase satisfaction of educators } \\
\text { Continue to teach in MUHAS } \\
\text { Prevent "brain drain" }\end{array}$ \\
\hline Environment & $\begin{array}{l}\text { Stakeholders of midwifery education } \\
\text { - } \quad \text { Tanzania Commission for Universities } \\
\text { - } \\
\text { Ministry of Health Nursing \& Midwifery } \\
\text { - } \quad \text { Council } \\
\text { - } \quad \text { Muhimbili University School Board } \\
\text { Poor working conditions and professional } \\
\text { development in Midwifery } \\
\text { - } \quad \text { Needs of EBP in Midwifery } \\
\text { - } \\
\text { - } \\
\text { - }\end{array}$ & $\begin{array}{l}\text { The new midwifery Master program } \\
\text { provide midwives an opportunity to } \\
\text { study EBP and advanced contents in } \\
\text { Master-level within the country }\end{array}$ & $\begin{array}{l}\text { The new program and graduates } \\
\text { are accepted in the country } \\
\text { - Job offer after graduation } \\
\text { - } \quad \text { Higher status of midwives } \\
\text { in society }\end{array}$ \\
\hline
\end{tabular}

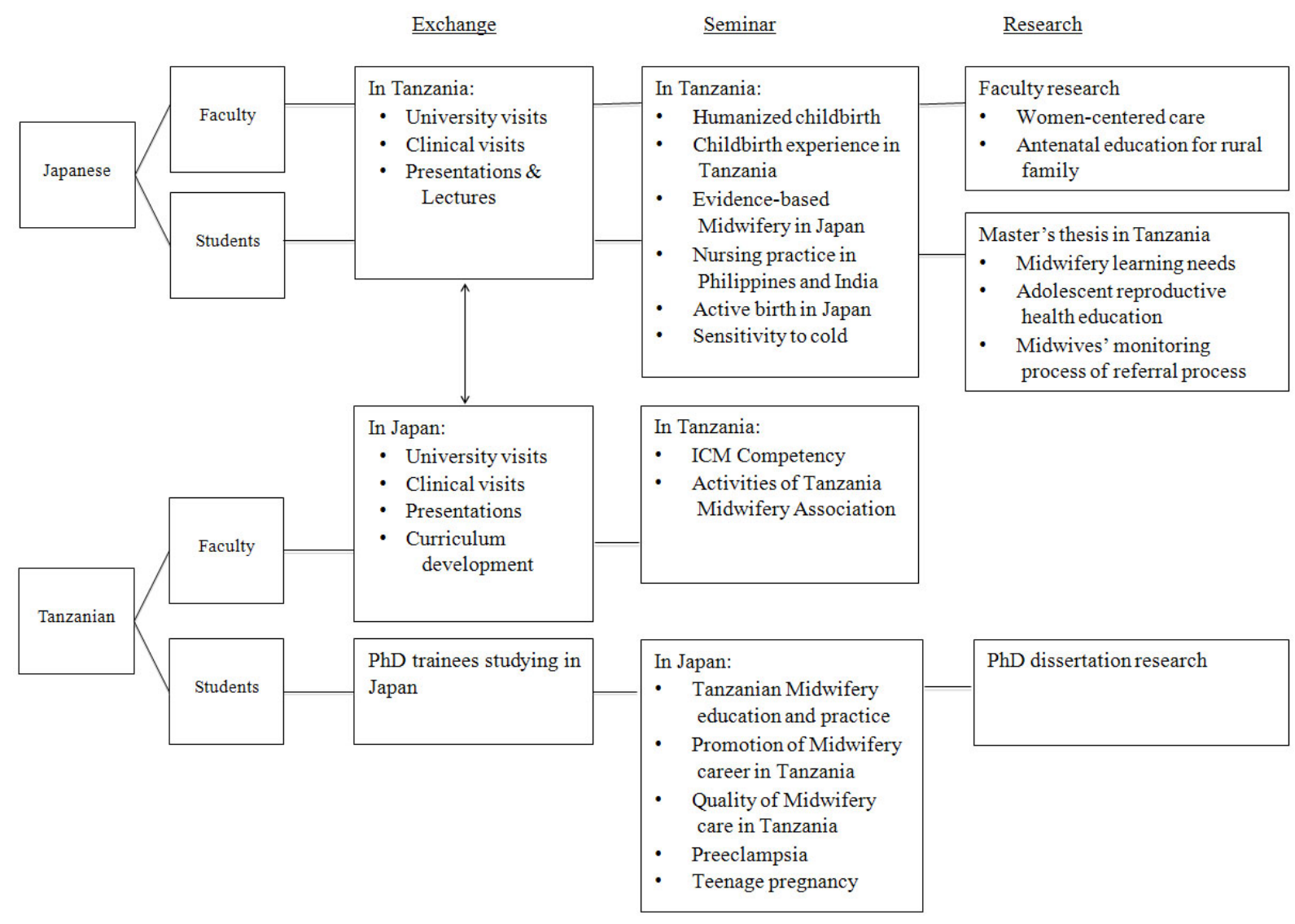

Figure 1. Outline of the project 


\subsection{Exchange program in Tanzania}

The faculty and graduate students from St. Luke's visited Tanzania each year. MUHAS faculty arranged for student interaction and clinical visits. The faculty and graduate students from St. Luke's visited MUHAS School of Nursing and Muhimbili National Hospital providing presentations to nursing/midwifery students, nurses and midwives. The presentation titles were published elsewhere. ${ }^{[26]}$ Japanese faculty and graduate students also visited the more rural district of Bagamoyo for field observation as the Bagamoyo District Hospital has a collaborative relation with MUHAS. They visited a dispensary, a health center, and the district hospital so that students learned not only about the national referral hospital at Muhimbili, but also the smaller community health facilities.

\subsection{Seminar}

Each time the MUHAS faculty visited St. Luke's, they held a seminar for Japanese students and faculty to learn about the situation in Tanzania. For the first year, this was the opportunity to introduce the start of collaboration and to evaluate the outcome of the collaborative curriculum development. During the seminars, the following were suggested: 1) the concept of evidence-based practice should be applied to the entire curriculum; 2) the goal of the master's program should be the development of translational researchers because the length of master's program is not enough to develop independent researchers and 3) to increase feasibility and sustainability of the program, some courses should be merged with other curricula that will be taught together as a group.

When St. Luke's faculty and graduate students visited Tanzania in 2012, a two-day joint seminar on humanized childbirth was held just north of the capital, Dar es Salaam, at Kunduchi Beach. More than 120 Tanzanian midwives gathered at the seminar to learn about the new concept of humanized childbirth. ${ }^{[27]}$ After learning about the concept and midwifery practices in Japan, Tanzanian midwives discussed how they could implement the concept in their everyday practice. Their answers included the following: change in midwives (share knowledge and information, change attitudes toward clients, different delivery positions), improve environment (increase midwives, provide onsite midwifery supervisors, discussions with managers, influence policy makers), and conduct more research (conduct studies in Tanzania, identify gaps, training on evidence-based practice). It was an opportunity for midwives in Tanzania to reflect on their practice and to think about improvement by their own efforts. The presentation titles during the project were listed in Table 2.

\subsection{Research collaboration}

The outcomes of the humanized childbirth seminar in 2012 were evaluated using a pre-/post-test evaluation and are under publication process. MUHAS faculty collaborated with St. Luke's students by facilitating the research approval process and entry into the field for research. In 2013, three master's students from St. Luke's completed their degrees after submitting their theses on Tanzanian health issues. ${ }^{[28-30]}$ Another student also conducted a master's research in Tanzania in 2014.

Table 2. List of presentation titles

\begin{tabular}{|c|c|c|}
\hline & Midwifery education, practice, and projects & Midwifery research \\
\hline \multirow{3}{*}{2011} & Midwifery education and practice in Tanzania [TZ] & $\begin{array}{l}\text { Translating global recommendations on HIV and infant feeding to the } \\
\text { local context: The development of culturally sensitive counseling tools in } \\
\text { the Kilimanjaro Region, Tanzania [TZ] }\end{array}$ \\
\hline & $\begin{array}{l}\text { Report of the International Confederation of Midwives (ICM) } \\
\text { Triennial Conference in Durban, South Africa [JP] }\end{array}$ & Competencies of researchers and its educational program [US] \\
\hline & $\begin{array}{l}\text { Introducing the action plan of the Center of Asia Africa Midwifery } \\
\text { Research [TZ, JP] }\end{array}$ & \\
\hline \multirow{4}{*}{2012} & Introducing the concept of Humanized Childbirth [JP] & Evidence-based Midwifery in Japan [JP] \\
\hline & Teenage pregnancy in the Philippines [JP] & Childbirth experience in Haydom, Mbulu Tanzania [JP] \\
\hline & ICM Twinning Project [TZ] & \\
\hline & Updates on Scope of Midwifery practice ICM/Tanzania [TZ] & \\
\hline \multirow{3}{*}{2013} & Midwifery practice in Tanzania [TZ] & \\
\hline & $\begin{array}{l}\text { Campaign to promote Midwifery as career among secondary school } \\
\text { youths in Tanzania [TZ] }\end{array}$ & \\
\hline & $\begin{array}{l}\text { Mentoring Nusing and Midwifery students at Muhimbili National } \\
\text { Hospital [TZ] }\end{array}$ & \\
\hline \multirow[b]{2}{*}{2014} & Eclampsia: Muhimbili National Hospital - Tanzania [TZ] & Mixed-Methods: Qualitative \& Quantitative Analytical Models [US] \\
\hline & Teenage pregnancy [TZ] & $\begin{array}{l}\text { Waiting for attention and care: Birthing accounts of women in Tanzania } \\
\text { who developed fistula as an outcome of labour [TZ] }\end{array}$ \\
\hline
\end{tabular}




\subsection{Launch of master's programme in midwifery and women's health}

After we collaboratively developed and revised the curriculum of the midwifery master's program in 2011, MUHAS faculty held a stakeholder meeting with the Ministry of Health, Medical and Nursing Associations, nursing and midwifery educators, clinical midwives, and development donors. From the discussion with stakeholders, the following were suggested: 1) The curriculum should be in line with a scope of practice that would be developed with International Congress Midwives consultants in 2012; 2) Prospective students must be those who want to dedicate their life to midwifery care, rather than those who have long experience as a midwife; 3) To develop clinical instructors, MUHAS should provide the training for the clinical instructors who have long-term experiences in lieu of advanced education because there were no master's-prepared midwives in the clinical settings and 4) MUHAS needs to entertain the possibility of receiving assistance from physicians or foreign midwifery educators. With these suggestions, MUHAS complied all the required documents to start the new program.

As suggested by the Tanzania Commission for Universities, MUHAS had to solve the issue of faculty shortage to start the new program. Therefore, St. Luke's faculty agreed to be visiting professors. Thus, after three years of effort, the Master's program in Midwifery and Women's Health started in October 2014. Nine students were enrolled in the program. A St. Luke's faculty gave a lecture on Humanized Childbirth and in-class practice in December 2014. On December 8th, 2014, we held the ceremony to officially launch the program to which the Ambassador of Japan and JICA representatives were invited and attended. The JICA expert, Dr. Tomohiko Sugishita gave the keynote speech at the ceremony, "A Path to Universal Health Coverage through Transformative Learning in Midwifery." He emphasized the importance of nurses and midwives taking leadership roles to make a transformation in the society.

\subsection{Steps forward}

As of 2014, we completed the first five years of our sisterschool relationship and renewed the Memorandum of Understanding for another five years. We plan to start a joint master's program beginning in April 2015, which includes sending St. Luke's master's students as JICA volunteers to stay for two years in Tanzania. The program will last until the last cohort will complete the degree in 2023. We are also accepting a PhD student from MUHAS faculty to develop their capacity in teaching and research.

We identified 5 keys for success of our collaborative project:

(1) Spending adequate time for in-person communica- tion with the collaborative partner: We spent a significant amount of time together visiting both sides. Distance communication was only by emails; sometimes it took time to receive a simple response, or responses would be forgotten in the crunch of our heavy workloads. Hence, in-person communication progressed the project even after a short stagnation. Also, by visiting on-site and watching the situation, it became easier to understand the other side, which prevented miscommunication and dissolved misunderstandings.

(2) Share the same goals and concepts: The clear goal of establishing a master's program kept us "on the same page". All partners involved were pragmatic and goal-oriented; this trait might be in common as a nursing profession. When the Japanese side discovered that the entire Tanzanian faculty liked the concept of Humanized Childbirth and adopted it as the core concept of the curriculum, it created group solidarity and clarified what we wanted to achieve through this new program. It is important to set goals and underlying concepts in the way that all participants understand and agree so that the motivation will be enhanced.

(3) Understanding different values and norms for working and living: As we live in a different culture and different landscapes, we have different values and norms. For example, Japanese are punctual regardless, while Tanzanians might delay at any time to help their friends or relatives. Tanzanian faculty showed up on time when they visit St. Luke's university, and Japanese faculty and students tried to be more flexible when they visited MUHAS in Tanzania. Both cultures have different rules to follow for the universities and funding agencies. It is important to talk and discuss these differences when we found them before thinking that something was going wrong.

(4) Learning ways of communication and project implementation in partner's culture: In email communication, we both thank and talk positively at the beginning of the email because email communication might sound harsher than when we talk in-person. Also, we both are aware of the rules to conduct research in Tanzania: permission must be obtained from national institutions and local communities. In Tanzania, proper greetings are the most important matter for communication. Japanese students learned how to greet in Swahili so that they would be accepted in the community. Tanzanian faculty learned how to greet in Japanese to show their respect.

(5) Confirm the feasibility, which can increase team 
members' motivation and commitment: Lecturing on Humanized Childbirth for Tanzanian faculty was effective because they believed that if Brazil could make changes in 90 's, they might be able to make changes in Tanzania. If they just saw maternal child health care situations in Japan, they would think that Humanized Childbirth is only for developed countries. Sharing examples from India and the Philippines in the Humanized Childbirth Seminar helped to motivate midwives to discuss how they might implement the concept in Tanzania. It is important that all of those involved believe that they can achieve the shared goal.

\section{Discussion}

Comparing our experiences with De Santis' concept ${ }^{[18]}$ we have accomplished second, third and fourth elements: (2) We created the project according to the needs of the host country, identifying available human and organizational resources which were ready and had high potential to develop for higher education; (3) We used an input-output model to examine sociocultural, political and economic factors that were likely to affect the outcomes of the project and (4) Both groups were involved in the partnership with the travel to one another for the face-to-face communication. Of particular note was that the observation of Japanese midwifery education and practice as well as understanding the concept of Humanized Childbirth significantly motivated the young faculty from Tanzania to work on this project. We shared the same goals and values, saying that it is important to advance midwifery education and implement Humanized Childbirth to improve quality of care for mothers and babies.

However, our current aim did not match the first of De Santis' concept, negate the need for the donor group in the host country, as the donor country, has gained as much in terms of learning midwifery in another country and conducting research together. We understand the concerns of De Santis' where nurses from the donor country often developed projects based on their own needs, rather than that of the host country. To address these issues, De Santis emphasized the importance of altruism in international projects; however, we believe for 21 st century international projects, both sides need to take something out of the collaboration as equal partners. In other words, both countries should become a donor country.

Conducting collaborative research creates opportunities for both sides to learn and make visible achievements. ${ }^{[21]}$ Using research funds for addressing health issues in the host country would fill the '90/10 gap' in global health; that gap means that less than $10 \%$ of the world's health research funds are spent on diseases that affect $90 \%$ of the world's population. ${ }^{[31]}$

Leffers and Mitchell's ${ }^{[32]}$ concept analysis of partnership and sustainability in global health indicates that nurses from the donor country bring expertise from knowledge or advanced technology available in the country; however, they would not have all the solutions in the host country and must be humble enough to learn from the host partner's knowledge. This notion was consistent with the concept described as cultural humility by Miller. ${ }^{[33]}$ This concept was originally developed in client-provider relationship in U.S. Cultural humility means that a continual process of self-refection and self-critique that overtly addresses power inequities between providers and clients is necessary. Cultural humility allowed growth and development as well as mutual understanding among students and faculty through providing opportunities to reflect on their own values and beliefs about cultural differences. ${ }^{[34]}$

This concept of cultural humility is similar to the concept of People-Centered Care (PCC), upon which St. Luke's education and research are based. The concept was derived from WHO WPRO's statement in 2007. ${ }^{[35]}$ We define PCC as the care in which people are the main actors and individuals autonomously create or protect their own health through partnerships between people and health care providers. In PCC, health care providers must be humble enough to learn from their clients. Therefore, even for this international project, we naturally thought and acted based on PCC as we understood that people in the host country are the most knowledgeable about their own needs and health of the community.

In addition to this successful relationship factor, Leffers and Mitchell ${ }^{[32]}$ also suggested enabling factors for international projects such as resources and project inputs (e.g., community assessment, organizational setting, host community, leadership champion, and project ownership). We obtained timely financial resources and human resources: a Tanzanian international student at St. Luke's, a faculty supervisor for a Tanzanian graduate student who was willing to continue to support Tanzania, a junior faculty who conducted research in Tanzania, and graduate students with experience as JICA volunteers and were seeking opportunities to conduct research in Africa. All these human resources were available at the beginning phase and strengthened the project's factor inputs. The chair of the project prepared for the organizational setting of St. Luke's to simultaneously implement exchanges and research. The junior faculty bridged the two countries and led the exchanges at both sites.

In hindsight, multiple factors, both planned and fortuitous happened, which brought us to a strong successful start of 
the new master's program. We trusted this would ensure lasting and sustainable outcomes as we decided to continue our collaboration for the next 5 years. As other researchers indicated, ${ }^{[20]}$ we also faced some challenges including geographical distance, miscommunication, and heavy workload as faculty therefore having limited time for the project. Hence, the outcomes would not have been achieved without the continuous efforts between the two institutions and other stakeholders. The issues and progress was reported elsewhere. ${ }^{[36-40]}$ Moving forward, the project is expanding with new players including JICA volunteers from St. Luke's and international students from MUHAS, who will deeply strengthen the trusting relationships and provide for conducting activities in the long term.

\section{Limitations}

Although the project has been continuing for almost 4 years, the new Midwifery Master's program in MUHAS has just started. The ultimate outcome of the input-output model for advancement of midwifery profession has yet to be evaluated. The findings presented in this article are mostly anecdotal and interim data. The research articles from the collaboration are still under publication process. Continuing commitment is necessary to make more visible outcomes.

\section{Conclusion}

The project of Asia Africa Midwifery Research Center achieved the original goal to start the Midwifery Master's program. Many successful factors facilitated the project; the project was based on the needs of the host country; community assessment was done with novice researchers to bridge the two institutions; the chief set the organizational setting; and project ownership was shared between two institutions with clear goals.

The exchange programs, seminars, and research collaboration between two institutions built trust, which led to continuing and sustainable relationship. This was accomplished by the efforts of the both institutions, and both gained knowledge and research outcomes as well as the satisfaction of establishing the master's program. Our values of humanized childbirth and people-centered care worked naturally to progress the project.

After completion of the master's program, graduates will begin enacting their midwifery leadership roles. Plus, the new players from St. Luke's and MUHAS will join to strengthen the collaboration. This partnership model, with egalitarian relationships is a good example of 21 st Century international collaboration to improve midwifery care and reduce maternal mortality in Tanzania. Although this project seems a small step, we hope this one step will make an impact on reducing the burdens of maternal mortality in Sub-Saharan Africa.

\section{ACKNOWLEDGements}

We thank all participants who shared their valuable time for this project. Our sincere gratitude goes to Dr. William Holzemer who provided advice on developing higher education. Dr. Sarah E. Porter provided editing on behalf of St. Luke's International University. The Japan Society for the Promotion of Science, Asia Africa Science Platform Program (2011-2014), Pfizer Health Research Foundation (2014-2015), Core-tocore program (2015-2018), and St. Luke's International University funded this project.

\section{CONFlicts of InTEREST Disclosure}

The authors declare that they have no competing interests.

\section{REFERENCES}

[1] Rosenfield A, Maine D. Maternal mortality-a neglected tragedy. Where is the $\mathrm{M}$ in $\mathrm{MCH}$ ? Lancet. 1985; 2(8446): 83-5. http: //dx.doi.org/10.1016/S0140-6736(85)90188-6

[2] United Nations. The Millennium Development Goals Report 2014. New York: United Nations; 2014.

[3] National Bureau of Statistics (NBS) [Tanzania] and ICF Macro. Tanzania Demographic and Health Survey 2010. Dar es Salaam, Calverton: NBS and ICF Macro; 2011.

[4] World Health Organization. Making pregnancy safer: the critical role of the skilled attendant. A joint statement by WHO, ICM and FIGO. Geneva: WHO; 2004.

[5] Häggström E, Mbusa E, Wadensten B. Nurses' workplace distress and ethical dilemmas in Tanzanian health care. Nurs Ethics. 2008; 15(4): 478-91. PMid:18515437 http://dx.doi .org/10.1177/0 969733008090519
[6] Nyamtema AS, Urassa DP, van Roosmalen J. Maternal health interventions in resource limited countries: a systematic review of packages, impacts and factors for change. BMC Pregnancy Childbirth. 2011; 11: 30. http://dx.doi.org/10.1186/1471-2393-11-3 0

[7] Olsen ØE, Ndeki S, Norheim OF. Human resources for emergency obstetric care in Northern Tanzania: distribution of quantity or quality? Hum Resour Health. 2005; 3: 5. http://dx. doi .org/10.11 86/1478-4491-3-5

[8] United Nations Population Fund. The World's Midwifery 2014: a universal pathway. A women's right to health. New York: UNFPA; 2014.

[9] Kinfu Y, Dal Poz MR, Mercer H, et al. The health worker shortage in Africa: Are enough physicians and nurses being trained? Bull World Health Organ. 2009; 87: 225-30. http://dx.doi.org/10.2471 /BLT.08.051599

[10] Freedman LP, Ramsey K, Abuya T, et al. Defining disrespect and 
abuse of women in childbirth: a research, policy, and rights agenda. Bull World Health Organ. 2014; 92: 915-917. http://dx.doi.o $\mathrm{rg} / 10.2471$ /BLT.14.137869

[11] World Health Organization. The prevention and elimination of disrespect and abuse during facility-based childbirth. Geneva: WHO; 2014.

[12] McMahon SA, George AS, Chebet JJ, et al. Experiences of and responses to disrespectful maternity care and abuse during childbirth; a qualitative study with women and men in Morogoro Region, Tanzania. BMC Pregnancy Childbirth. 2014; 14: 268. http: //dx.doi.org/10.1186/1471-2393-14-268

[13] World Health Organization. Care in normal birth: a practical guide. Geneva: WHO; 1996.

[14] Mselle L, Kohi TW, Mvungi A, et al. Waiting for attention and care: birthing accounts of women in rural Tanzania who developed obstetric fistula as an outcome of labour. BMC Pregnancy Childbirth. 2011; 11:75. http://dx.doi.org/10.1186/1471-2393-11-75

[15] Shimpuku Y, Patil CL, Norr KF, et al. Women's perceptions of childbirth experience at a hospital in rural Tanzania. Health Care Women Int. 2013; 34(6): 461-81. PMid:23470119 http://dx.doi .org/1 $0.1080 / 07399332.2012 .708374$

[16] Dawson A, Brodie P, Copeland F, et al. Collaborative approaches towards building midwifery capacity in low income countries: a review of experiences. Midwifery. 2014; 30(4): 391-402. http: //dx.doi.org/10.1016/j.midw.2013.05.009

[17] World Health Organization. WHO Global Code of Practice on the International Recruitment of Health Personnel. Geneva: WHO; 2010. Available from: http://www . who.int/hrh/migration/code/c ode_en.pdf

[18] De Santis L. A model for counterparts in international nursing. Int J Nurs Stud. 1995; 32(2): 198-209. http://dx.doi .org/10.1016 10020-7489 (94) E0006-5

[19] George EK, Meadows-Oliver M. Searching for collaboration in international nursing partnerships: a literature review. Int Nurs Rev. 2013; 60(1): 31-6. http://dx.doi.org/10.1111/j.1466-765 $7.2012 .01034 . \mathrm{x}$

[20] Anderson F, Donkor P, de Vries R, et al. Creating a charter of collaboration for international university partnerships: the Elmina declaration for human resources for health. Acad Med. 2014; 89(8): 1125-32. PMid:24918757 http://dx.doi .org/10.1097/ACM. 0 000000000000384

[21] Kaddumukasa M, Katabira E, Salata RA, et al. Global medical education partnerships to expand specialty expertise: a case report on building neurology clinical and research capacity. Hum Resour Health. 2014; 12(1): 75. http://dx. doi.org/10.1186/1478-4 491-12-75

[22] Buchan J, Calman L. The global shortage of registered nurses: an overview of issues and actions. Geneva: International Council of Nurses (ICN). 2004

[23] Madeni F, Horiuchi S, Iida M. Evaluation of a reproductive health awareness program for adolescence in urban Tanzania-a quasiexperimental pre-test post-test research. Reprod Health. 2011; 8: 21. PMid:21707996 http://dx.doi.org/10.1186/1742-475 5-8-21

[24] Shimpuku Y, Horiuchi S, Leshabari S, et al. Collaboration between Japanese and Tanzanian midwives to develop the first midwifery master's course in Muhimbili University of Health and Allied Science, Tanzania: a case report. 2011 Joint Conference: 52nd Annual Meeting of the Japanese Society of Tropical Medicine, 26th Annual Meeting of Japan Association for International Health; Tokyo, Japan. Programs and Proceedings. 2011. 114.
[25] Misago C, Umenai T, Onuki D, et al. Humanised maternity care. Lancet. 1999; 354(9187): 1391-92. http://dx.doi.org/10.10 16/S0140-6736(05) 76250-4

[26] Shimpuku Y, Fumoto A, Oba K, et al. Expansion of the international cooperation seminar in women's health and midwifery, the graduate program, to the context of Tanzania. Bulletin of St. Luke's International University. 2015. in press. [Japanese]

[27] WHO Collaborating Centre for Nursing Development in Primary Health Care. JSPS Asia Africa science platform program: the joint seminar in Tanzania. Nursing \& Midwifery Links. 2012; 16-18. Available from: http://200.144.255.73:8000/globalnet/nml_d ec2012.pdf

[28] Shimoda K. Midwives' intrapartum monitoring process and management resulting in emergency referrals in Tanzania [master's thesis] [Tokyo, Japan]: St. Luke's International University; 2014.

[29] Tanaka N. Midwives' expectations and learning needs for professional development in Tanzania [master's thesis]. [Tokyo, Japan]: St. Luke's International University; 2014.

[30] Itokawa A. Evaluation of a reproductive health awareness program for a quasi-experimental pre-test post-test research adolescence in rural Tanzania [master's thesis]. [Tokyo, Japan]: St. Luke's International University; 2014.

[31] Resnik DB. The distribution of biomedical research resources and international justice. Dev World Bioeth. 2004; 4: 42-57. PMid:15086373 http://dx.doi.org/10.1111/j.1471-8731. 2004.00066 . $\mathrm{x}$

[32] Leffers J, Mitchell E. Conceptual model for partnership and sustainability in global health. Public Health Nurs. 2011; 28(1): 91-102. http://dx.doi.org/10.1111/j.1525-1446.2010.00892.x

[33] Miller S. Cultural humility is the first step to becoming global care providers. J Obstet Gynecol Neonatal Nurs. 2009; 38(1): 92-3. http://dx.doi.org/10.1111/j.1552-6909.2008.00311.x

[34] Foster J. Cultural humility and the importance of long-term relationships in international partnerships. J Obstet Gynecol Neonatal Nurs. 2009; 38(1): 100-7. http://dx.doi.org/10.1111/j.1552-690 9.2008.00313.x

[35] World Health Organization. Regional Office for the Western Pacific People-centred health care: a policy framework. Manila: WHO WPRO; 2007.

[36] Shimpuku Y, Horiuchi S, Leshabari S, et al. Process report of a collaborative project between Tanzania and Japan to develop a master's program in midwifery. The 9th International Conference of the Global Network of WHO Collaborating Centres for Nursing and Midwifery; Kobe, Japan. 2012.

[37] Shimpuku Y, Horiuchi S, Leshabari S, et al. Starting a midwifery master's programme in Tanzania: lesson learned from the collaborative project between Tanzania and Japan. The East, Central, and Southern African College of Nursing the 10th Scientific Conference; Port Louis, Mauritius. 2012.

[38] Wakai S, Shimpuku Y, Iida M, et al. Tanzanian midwives' perceptions of women-centered care at humanized childbirth seminar. The 27th Japan Academy of Midwifery; Kanazawa, Japan. 2013.

[39] Takeuchi S, Shimoda K, Takahata K, et al. Midwives' perceptional changes at the humanized childbirth seminar in Tanzania. The 15th Japan Academy of Human Care Conference; Tokyo, Japan. 2013.

[40] Shimpuku Y, Horiuchi S, Matsutani M, et al. Partnership model of global collaboration: the shared value of humanized childbirth in Tanzania. The 17th East Asian Forum of Nursing Scholars; Manila, Philippines. 2014. 